\title{
Surgical Outcomes of Rhegmatogenous Retinal Detachment with Different Peripheral Vitreous-Shaving Procedures
}

\author{
Koichi Nishitsuka ii \\ Madoka Nakamura \\ Katsuhiro Nishi \\ Hiroyuki Namba \\ Yutaka Kaneko \\ Hidetoshi Yamashita \\ Department of Ophthalmology and \\ Visual Sciences, Yamagata University \\ Faculty of Medicine, Yamagata, Japan
}

Correspondence: Koichi Nishitsuka Department of Ophthalmology and Visual Sciences, Yamagata University Faculty of Medicine, Yamagata City, Japan

Tel +8I 23-628-5374

Fax +8I 23-528-5377

Emailmlc12186@nifty.com
Purpose: To compare the surgical outcomes of vitreous surgery for rhegmatogenous retinal detachment (RRD) after two different peripheral vitreous-shaving techniques are performed. Methods: We reviewed 269 eyes with RRD that were treated with a 25-gauge vitrectomy by a single surgeon between June 2015 and May 2020. The exclusion criteria for the proposed air tamponade selection were as follows: more than two weeks since RRD onset, giant retinal tears, a history of complications following cataract surgery, high myopia, and proliferative vitreoretinopathy classified as grade $\mathrm{C}$ or higher. We examined the differences in the therapeutic effect between shaving under slit lamp microscope illumination (group A) and shaving under a wide-angle viewing system (group B).

Results: A total of 269 eyes were included in this study, with 146 eyes in group A and 123 eyes in group B. The primary anatomical success rates did not differ between group A $(97.3 \% ; 142 / 146$ eyes $)$ and group B $(97.6 \% ; 120 / 123$ eyes; $P=0.102)$. However, the surgical time was significantly longer in group A $(60.2 \pm 17.1 \mathrm{~min})$ than that in group B (46.9 $\pm 12.6 \mathrm{~min})(\mathrm{P}<0.001)$. The multiple linear regression analysis revealed that surgical time was significantly correlated with using the wide-angle noncontact viewing system for vitreous shaving (adjusted $R^{2}=0.248$; beta [standard partial regression coefficient] $=-0.447$, $P<0.001$ ), the number of retinal breaks (beta $=0.182, P=0.001$ ), and the quadrant of retinal detachment (beta $=0.205, P<0.001$ ).

Conclusion: The surgical outcomes were similar regardless of the shaving procedure performed, and the surgical time was shortened by using the wide-angle noncontact viewing system for vitreous shaving.

Keywords: vitrectomy, vitreous base, posterior vitreous-cortex detachment, slit lamp microscope illumination, wide-angle noncontact viewing system

\section{Introduction}

Rhegmatogenous retinal detachment (RRD) is a serious retinal disorder that can lead to blindness. Pars plana vitrectomy (PPV) has been gaining popularity for the treatment of primary RRD since $2008 .^{1,2}$ Several studies have reported an increase in the use of PPV for treating eyes with RRD. ${ }^{3-6}$ The Japan Retinal Detachment Registry revealed that in 2016 and 2017, vitrectomy was employed to treat $77.8 \%$ of RRD cases. ${ }^{7,8}$

The vitreous near the vitreous base was thought to be associated with the formation of retinal breaks, and in such cases peripheral vitreous shaving was performed to eliminate the traction of the vitreous to the retina. ${ }^{9-11}$ Two approaches 
can be used for vitreous shaving: an ocular indentation can be created to observe the periphery of the retina using either slit lamp microscope illumination or a wide-angle noncontact viewing system. Recently, Tabandeh et al reported the outcome of retinal detachment (RD) surgery without scleral-depressed shaving of the vitreous base. ${ }^{12}$ However, little is known regarding the extent of vitreous shaving that is appropriate in this context because no method is available to objectively quantify the residual vitreous.

To objectively observe the peripheral vitreous and retina, we developed a procedure using intraoperative optical coherence tomography (iOCT). ${ }^{13}$ We found that slit lamp microscope illumination resulted in enhanced vitreous shaving compared with the use of a wide-angle noncontact viewing system, possibly because of improved peripheral viewing. ${ }^{14}$ The purpose of this study was to examine the treatment results in response to different peripheral vitreous-shaving procedures for RRD.

\section{Materials and Methods}

This retrospective study was performed in accordance with the Declaration of Helsinki and was approved by the Ethics Committee of the Yamagata University Faculty of Medicine (approval number: H26-21). All data were fully anonymized before we accessed them, and the institutional review board waived the requirement for informed consent. We conducted a retrospective analysis of $269 \mathrm{RRD}$ eyes treated by a single surgeon (K Nishitsuka) between June 2015 and May 2020 using the following exclusion criteria for the proposed air tamponade selection: more than two weeks since onset, giant retinal tears, a history of complications following cataract surgery, high myopia, and proliferative vitreoretinopathy (PVR) classified as grade $\mathrm{C}$ or higher. The selected cases were treated using different vitreous-shaving procedures. Cases that were treated between June 2015 and April 2018 underwent shaving under slit lamp microscope illumination (Group A) whereas cases that were treated between May 2018 and May 2020 underwent shaving under a wideangle viewing system (Group B).

\section{Surgical Procedure of Vitrectomy for RRD Treatment}

Retrobulbar anesthesia was administered using $6 \mathrm{~mL}$ of a mixture of $2 \%$ lidocaine and $0.5 \%$ levobupivacaine. We used the 25GPPV wide-angle noncontact viewing system (Resight $^{\circledR}$; Carl Zeiss Meditec AG, Jena, Germany) with the
Constellation Vision System (Alcon Laboratories, Inc., Fort Worth, TX, USA) or the EVA vitrectomy system (DORC, Zuidland, The Netherlands). We created three cannulas with conjunctival displacement and oblique-angled sclerotomies in the inferotemporal, superotemporal, and superonasal quadrants 3.0 to $4.0 \mathrm{~mm}$ posterior to the limbus. Before performing the vitrectomy, all phakic eyes underwent phacoemulsification and intraocular lens implantation (PEA + IOL) with a sclerocorneal incision using the same machine. After core vitrectomy, the vitreous gel was visualized with an injection of triamcinolone acetonide (MaQaid, Wakamoto Pharmaceutical, Tokyo, Japan) during midperipheral vitrectomy. Vitreous shaving around the retinal break with ocular indentation was performed under slit lamp microscope illumination (Visulux; Zeiss, Oberkochen, Germany) in group A (Figure 1), and under a wide-angle noncontact viewing system using chandelier endoillumination (TotalView Chandelier; DORC, Zuidland, The Netherlands) in group $\mathrm{B}$ (Figure 2). The peripheral vitreous gel then underwent

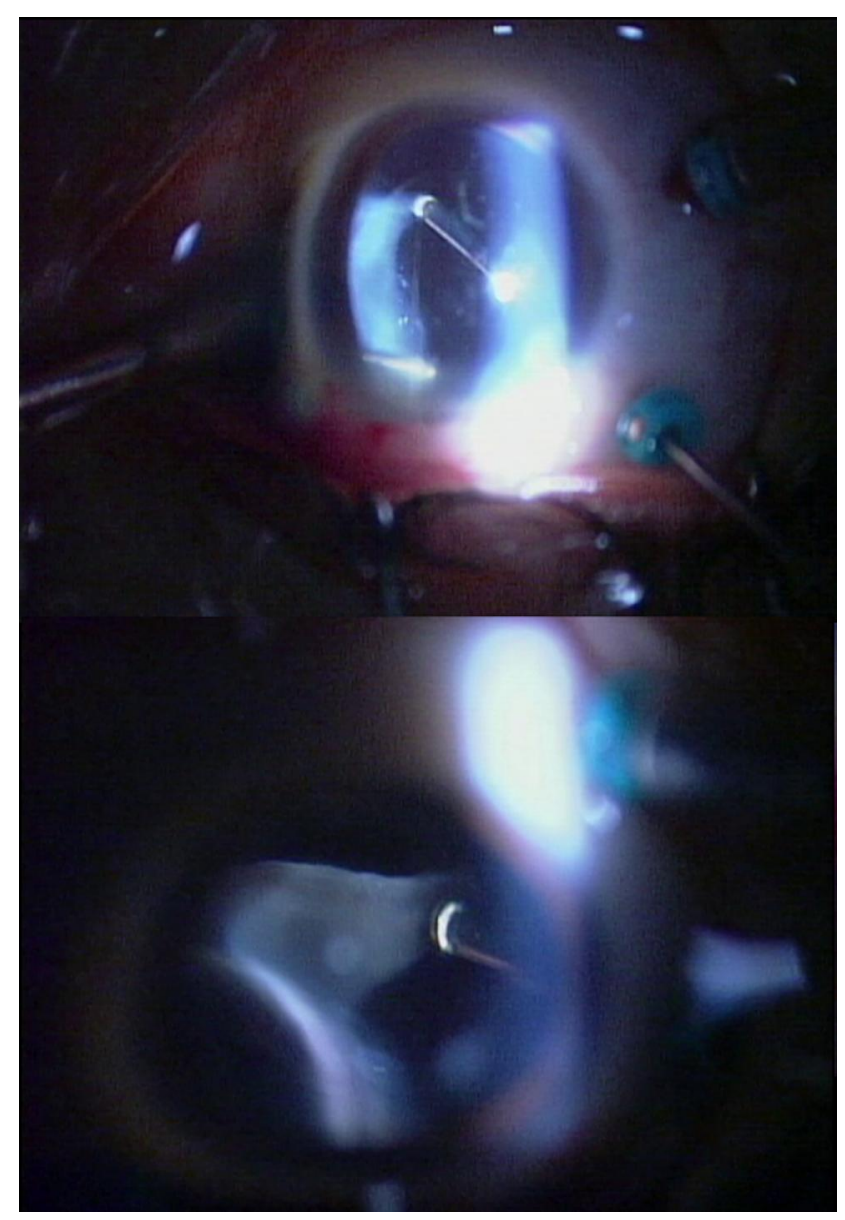

Figure I Vitreous shaving with ocular indentation under slit lamp microscope illumination. 


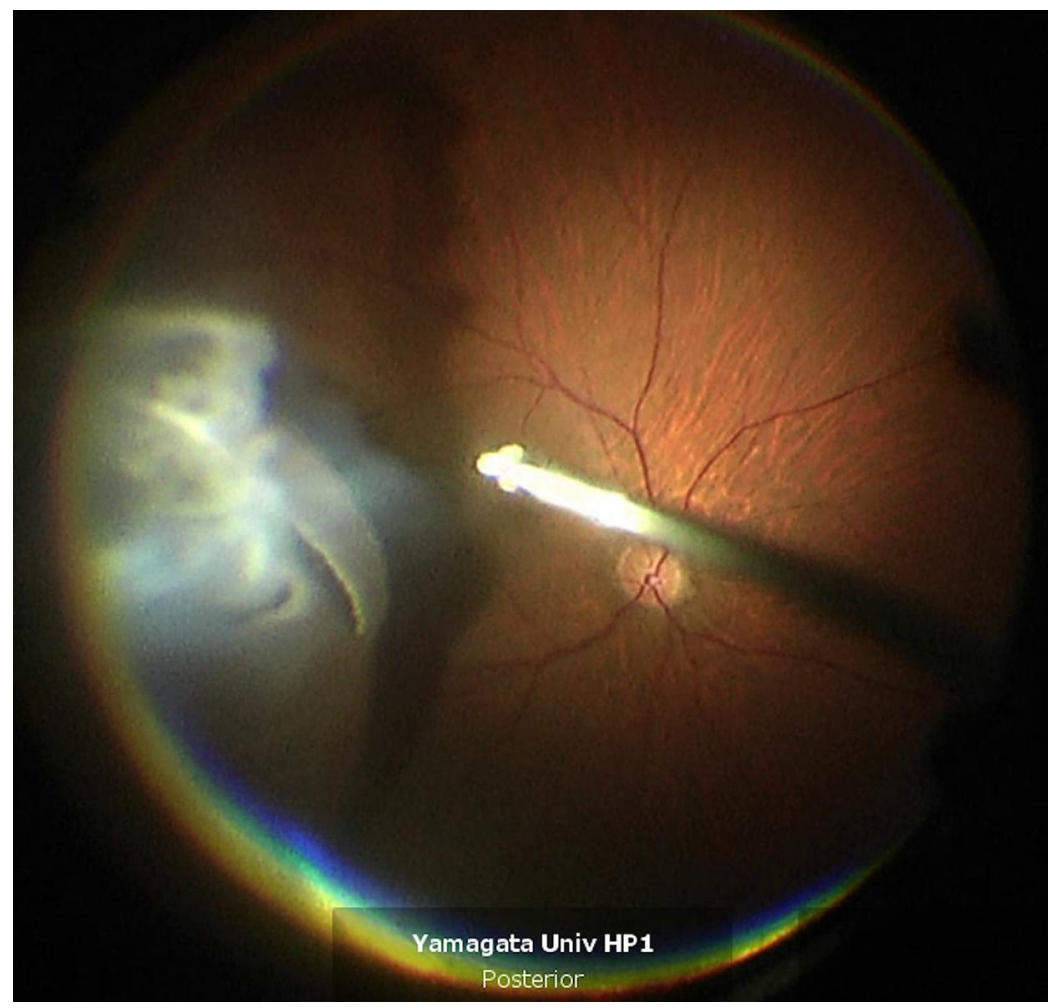

Figure 2 Vitreous shaving with ocular indentation under a wide-angle noncontact viewing system using chandelier endoillumination.

careful $360^{\circ}$ shaving with scleral indentation. An internal drainage retinotomy was not performed. All RDs were restored intraoperatively. To completely surround all retinal breaks, we applied retinal photocoagulation after fluid-gas exchange. All sclerotomy sites were closed with 8-0 Vicryl sutures. All patients were treated by hospitalization and had a daily fundus examination after the surgery. We encouraged all patients to assume a prone position following surgery and to remain prone until the intraocular gas concentration was reduced in half. Subsequently, all patients were permitted to assume any position, except for the supine position, until the intraocular gas disappeared.

\section{Data Collection}

The following patient demographic data were collected: age, sex, laterality of the eyes, time to surgery, number of retinal breaks, quadrant of $\mathrm{RD}$, location of retinal breaks, lens status, macular status, procedure used to perform the vitreous shaving, surgical time, and primary success for RD.

\section{Statistical Analyses}

The statistical analyses were performed using Fisher's exact test, the Chi-square test, and the Mann-Whitney $U$-test. We performed a multivariate linear regression analysis to identify potential factors that influence the differences of vitreous shaving results $(\mathrm{P}<0.05$ for selective criterion). For all analyses, $\mathrm{P}<0.05$ was statistically significant. All statistical data were analyzed using PASW Statistics 18 (SPSS Inc., Chicago, IL, USA).

\section{Results}

A total of 269 eyes were evaluated in this study, including 146 eyes in group A and 123 eyes in group B. Table 1 shows the patient characteristics and comparison of surgical outcomes between group A and group B. There were 47 women in group $\mathrm{A}$ and 33 in group $\mathrm{B}(P=0.352)$. The mean \pm standard deviation (SD) age was $63.3 \pm 9.7$ years in group $\mathrm{A}$ and $62.1 \pm 10.5$ years in group $\mathrm{B}(P=0.278)$. There was a mean $\pm \mathrm{SD}$ of $1.7 \pm 1.1$ retinal breaks in group A and $2.1 \pm 1.4$ in group B $(P=0.01)$. A total of 41 eyes $(28.1 \%)$ in group $A$ and $36(29.3 \%)$ in group B displayed lower breaks $(P=0.893)$. The mean \pm SD quadrant of RD was $1.7 \pm 0.7$ in group $A$ and $1.9 \pm 0.8$ in group B $(P=0.016)$. A total of 68 eyes $(46.6 \%)$ in group A and $72(58.5 \%)$ in group B displayed macular detachment $(P=0.066)$. There were 118 phakic eyes $(78.1 \%)$ in group A and $97(78.9 \%)$ in group B $(P=1)$. The primary success rates were similar in group A $(97.3 \% ; 142 / 146$ 
Table I Patient Demographics of Preoperative and Intraoperative Ophthalmologic Findings, and Comparison of Surgical Outcomes After RD Treatment Between Group A and Group B

\begin{tabular}{|l|l|l|l|}
\hline & $\begin{array}{l}\text { Group A } \\
\text { N = I46 }\end{array}$ & $\begin{array}{l}\text { Group B } \\
\text { N = I 23 }\end{array}$ & P value \\
\hline Age & $63.3 \pm 9.7$ & $62.1 \pm 10.5$ & 0.278 \\
Sex (female) & $47(32.2 \%)$ & $33(26.8 \%)$ & 0.352 \\
Laterality (right) & $89(61.0 \%)$ & $90(73.2 \%)$ & 0.038 \\
Time to surgery & $1.269 \pm 0.463$ & $1.317 \pm 0.484$ & 0.448 \\
(week) & & & \\
Number of retinal & $1.7 \pm 1.1$ & $2.1 \pm 1.4$ & 0.01 \\
breaks & & & \\
Quadrant of RD & $1.7 \pm 0.7$ & $1.9 \pm 0.8$ & 0.016 \\
Lower retinal break & $41(28.1 \%)$ & $36(29.3 \%)$ & 0.893 \\
Macular status & $68(46.6 \%)$ & $72(58.5 \%)$ & 0.066 \\
(macula off) & & & 1 \\
Lens status (phakia) & $114(78.1 \%)$ & $97(78.9 \%)$ & 1 \\
Surgical time (min) & $60.2 \pm 17.1$ & $46.9 \pm 12.6$ & $<0.00 \mathrm{I}$ \\
Surgical success & $142(97.3 \%)$ & $120(97.6 \%)$ & 0.893 \\
\hline
\end{tabular}

Notes: Group A: vitreous shaving was performed under slit lamp microscope illumination with an ocular indentation. Group B: vitreous shaving was performed under a wide-angle noncontact viewing system using chandelier endoillumination with an ocular indentation.

Abbreviation: RD, retinal detachment.

eyes) and group B $(97.6 \% ; 120 / 123$ eyes; $P=0.102)$. However, the surgical time was significantly longer in group A $(60.2 \pm 17.1 \mathrm{~min})$ than it was in group B (46.9 $\pm 12.6 \mathrm{~min})(P<0.001)$. No anterior PVR complication was seen in all the patients.

Table 2 shows the multiple regression analysis of the surgical time and clinical variables for all cases included in this study. A shortened surgical time was significantly correlated with shaving using the wide-angle noncontact viewing system (adjusted $R^{2}=0.248$; beta [standard partial regression coefficient] $=-0.447, P<0.001)$. Moreover, the number of retinal breaks (beta $=0.182$, $P=0.001$ ) and the quadrant of RD (beta $=0.205, P<$ 0.001 ) were significantly correlated with an extended surgical time.

\section{Discussion}

Routine prophylactic, scleral-depressed shaving of the vitreous base has been advocated by many as part of PPV for primary RRD. ${ }^{10}$ Our previous study, which quantified the peripheral vitreous using iOCT, showed that the amount of residual vitreous differed according to the different shaving techniques used (slit lamp microscope illumination vs wide-angle noncontact viewing system). Shaving under slit lamp microscope illumination enabled
Table 2 Univariate and Multiple Regression Analysis of the Surgical Time and Clinical Variables in All Cases in This Study

\begin{tabular}{|l|l|l|l|l|}
\hline \multirow{2}{*}{ Independent Variable } & \multicolumn{2}{|l|}{$\begin{array}{l}\text { Univariate } \\
\text { Analysis }\end{array}$} & \multicolumn{2}{l|}{$\begin{array}{l}\text { Multivariate } \\
\text { Analysis }\end{array}$} \\
\cline { 2 - 5 } & $\beta^{\mathrm{a}}$ & $\boldsymbol{P}$ value & $\boldsymbol{\beta}^{\mathrm{a}}$ & $\boldsymbol{P}$ value \\
\hline Age & -0.24 & 0.690 & & \\
Sex (female) & 0.19 & 0.753 & & \\
Laterality (right) & -0.139 & 0.022 & -0.92 & 0.088 \\
Time to surgery & 0.019 & 0.762 & & \\
Number of retinal breaks & 0.124 & 0.042 & 0.182 & 0.001 \\
Quadrant of RD & 0.161 & 0.008 & 0.205 & $<0.00 \mathrm{I}$ \\
Lower retinal break & 0.093 & 0.127 & & \\
Macular status (macula & 0.079 & 0.196 & & \\
off) & & & & \\
Lens status (phakia) & 0.102 & 0.095 & & \\
Shaving with the wide- \\
angle noncontact viewing \\
system
\end{tabular}

Notes: Adjusted $R^{2}=0.248$ for the surgical time in the multiple linear regression analysis $(P<0.05)$. ${ }^{a}$ Standard partial regression coefficient.

Abbreviation: RD, retinal detachment.

the reduction of the more peripheral vitreous. Furthermore, slit lamp observation allowed a clearer focus on the peripheral vitreous than did the wide-angle noncontact viewing system. Additionally, shaving under slit lamp microscope illumination required a greater degree of indentation than did the wide-angle noncontact viewing system. The combination with the slit lamp allowed clear visualization of the peripheral vitreous. ${ }^{15}$ These aspects may explain the greater time required for surgery in group A (Table 1). Conversely, the wide-angle noncontact viewing system requires a lower degree of indentation to observe the peripheral part of the retina. This is advantageous for microincision vitrectomy surgery (MIVS) because the conjunctiva is preserved during this procedure, which hampers strong indentation. In this study, the surgical time was shorter in group B, in which the vitreous was shaved under the wide-angle noncontact viewing system (Table 1).

In turn, greater shaving of the peripheral vitreous might prevent the formation of a scaffold by the vitreous base and the subsequent development of future anterior PVR and contraction, which leads to new retinal tears and subsequent RD. However, in the present study, the primary success rate did not differ between groups $\mathrm{A}$ and $\mathrm{B}$ despite the different amounts of residual vitreous (Table 1). Thus, the therapeutic effect and the amount of vitreous shaving might not be proportional. A recent study of vitreous 
shaving without scleral indentation in RRD suggested that a sufficient effect can be obtained if appropriate vitreous shaving is performed. ${ }^{12}$ When performing vitreous shaving without scleral indentation, we believe that it is important to verify the amount of shaved vitreous to evaluate the optimum vitrectomy shaving. The use of iOCT for the peripheral vitreous and retina might be helpful for performing such a study objectively. ${ }^{13,14,16}$

The procedures in this study were all performed by the same surgeon, which eliminates the presence of surgeon bias. The use of a wide-angle noncontact viewing system, the number of retinal breaks, and the quadrant of RD were identified as independent factors related to surgery time, and the results were extremely reasonable. The current study showed that there was no difference in the primary success rate between using the wide-angle noncontact viewing system and slit lamp illumination. In this study, vitreous shaving was performed at not only retinal breaks but also at 360-degrees near the vitreous base in all patients. Our previous study showed that iOCT could detect retinal breaks that occur near the peripheral posterior vitreous detachment and vitreous base. ${ }^{14}$ We named this site the "vitreo-retinal angle" based on the findings of iOCT. $^{13,14,16}$ Retinal breaks may occur when the vitreous near the vitreo-retinal angle causes peripheral posterior vitreous detachment. Thus, 360-degree vitreous shaving may be effective in preventing new postoperative retinal breaks.

Treatment outcomes for RRD vary depending on complexity. ${ }^{17-23}$ In this study, the subjects had relatively uncomplicated RRD, and the treatment was performed to reduce the effect of the severity of the RRD pathology. In complicated $\mathrm{RD}$, the vitreous base may form a scaffold for the development of future anterior PVR. ${ }^{1,2,10,24}$ However, there is little evidence in the literature supporting this clinical impression. ${ }^{12}$ Moreover, there is still no clear evidence of a difference in treatment outcomes between shaving only at the retinal breaks and 360-degree shaving. However, this study provides evidence that the peripheral shaving procedure did not affect RRD treatment outcomes and development of anterior PVR, at least for uncomplicated RRD. Future studies must focus on complicated RD and make comparisons based on more detailed differences in surgical techniques.

This study has several limitations. Given the retrospective nature of the present study, some items, including the location of the retinal break, quadrants of $\mathrm{RD}$, lens status, and macular status, differed between groups A and B. The results of this study stem from a single surgeon, with no bias caused by the skill of the surgeon; however, the results may differ if this type of surgery is performed by different surgeons. Due to the surgical data from single surgeon, increased experience may affect surgical time. Future prospective studies based on the results of the present research should provide further validation of the effectiveness of vitreous shaving.

In summary, we compared surgical outcomes for RRD between the different peripheral vitreous-shaving techniques performed. We found no differences in the therapeutic effects exhibited by shaving using slit lamp microscope illumination or a wide-angle noncontact viewing system. The pathology of RRD, including the number of retinal breaks and quadrant of $\mathrm{RD}$, prolonged the surgical time, and the use of a wideangle noncontact viewing system shortened the surgical time required. Future prospective studies should be conducted to establish an appropriate procedure for vitreous shaving.

\section{Abbreviations}

iOCT, intraoperative optical coherence tomography; MIVS, microincision vitrectomy surgery; PPV, pars plana vitrectomy; PVR, proliferative vitreoretinopathy; RD, retinal detachment; RRD, rhegmatogenous retinal detachment; SD, standard deviation.

\section{Acknowledgments}

This work was supported by JSPS KAKENHI (grant JP25462704). The work was presented at the 59th Annual Meeting of Japanese Retina and Vitreous Society, 2020.

\section{Disclosure}

Koichi Nishitsuka reports personal fees from Santen Pharmaceutical Co., Ltd., RE MEDICAL, INC., Carl Zeiss Co., Ltd., Alcon, Inc., Novartis Pharma K.K., Kowa Company. Ltd., Johnson \& Johnson K.K./JJKK, SENJU Pharmaceutical Co., Ltd., SANWA KAGAKU KENKYUSHO CO., LTD., and HOYA CORPORATION, outside the submitted work. Mr Hidetoshi Yamashita reports grants from Atsuzawa Prosthesis Co., Ltd., Alcon Japan Ltd., Santen Pharmaceutical Co., Ltd., Eisai Co., Ltd., SENJU PHARMACEUTICAL Co., Ltd., B.L.J Company, Ltd., Bayer Yakuhin, Ltd., AMO Japan, NOVARTIS Pharma Japan, Trust Medical Co., Ltd., and Taisho Pharma Japan, outside the submitted work. The authors report no other conflicts of interest in this work. 


\section{References}

1. Lai MM, Ruby AJ, Sarrafizadeh R, et al. Repair of primary rhegmatogenous retinal detachment using 25 -gauge transconjunctival sutureless vitrectomy. Retina. 2008;28(5):729-734. doi:10.1097/ IAE.0b013e318162b01c

2. Martinez-Castillo V, Boixadera A, Garcia-Arumi J. Pars plana vitrectomy alone with diffuse illumination and vitreous dissection to manage primary retinal detachment with unseen breaks. Arch Ophthalmol. 2009;127(10):1297-1304. doi:10.1001/ archophthalmol.2009.254

3. Ho JD, Liou SW, Tsai CY, Tsai RJ, Lin HC. Trends and outcomes of treatment for primary rhegmatogenous retinal detachment: a 9-year nationwide population-based study. Eye (Lond). 2009;23(3):669-675. doi:10.1038/sj.eye.6703105

4. Wong CW, Wong WL, Yeo IY, et al. Trends and factors related to outcomes for primary rhegmatogenous retinal detachment surgery in a large Asian tertiary eye center. Retina. 2014;34(4):684-692. doi:10.1097/IAE.0b013e3182a48900

5. Smretschnig E, Falkner-Radler CI, Sporl J, Kivaranovic D, Binder S, Krepler K. Primary retinal detachment surgery: changes in treatment and outcome in an Austrian tertiary eye center. Ophthalmologica. 2017;237(1):55-62. doi:10.1159/000454889

6. Reeves MG, Pershing S, Afshar AR. Choice of primary rhegmatogenous retinal detachment repair method in US commercially insured and medicare advantage patients, 2003-2016. Am J Ophthalmol. 2018;196:82-90. doi:10.1016/j.ajo.2018.08.024

7. Sakamoto T, Kawano S, Kawasaki R, et al. Japan-Retinal Detachment Registry Report I: preoperative findings in eyes with primary retinal detachment. Jpn J Ophthalmol. 2020;64(1):1-12. doi:10.1007/s10384-019-00702-6

8. Nishitsuka K, Kawasaki R, Yamakiri K, et al. Preoperative factors to select vitrectomy or scleral buckling for retinal detachment in microincision vitrectomy era. Graefes Arch Clin Exp Ophthalmol. 2020;258(9):1871-1880. doi:10.1007/s00417-020-04744-2

9. Weiner AJ, Rao P, Williams G. Large traumatic retinal dialysis associated with prominent vitreous base avulsion. Ophthalmic Surg Lasers Imaging Retina. 2018;49(9):731. doi:10.3928/2325816020180831-14

10. Chaturvedi V, Basham RP, Rezaei KA. Scleral depressed vitreous shaving, 360 laser, and perfluoropropane (C3 F8) for retinal detachment. Indian $J$ Ophthalmol. 2014;62(7):804-808. doi:10.4103/0301-4738.138621

11. Kuhn F, Aylward B. Rhegmatogenous retinal detachment: a reappraisal of its pathophysiology and treatment. Ophthalmic Res. 2014;51 (1):15-31. doi:10.1159/000355077

12. Tabandeh H, London NJS, Boyer DS, Flynn HW Jr. Outcomes of small-gauge vitreoretinal surgery without scleral-depressed shaving of the vitreous base in the era of wide-angle viewing systems. $\mathrm{Br}$ $J$ Ophthalmol. 2019;103(12):1765-1768. doi:10.1136/bjophthalmol2018-313626

Clinical Ophthalmology

\section{Publish your work in this journal}

Clinical Ophthalmology is an international, peer-reviewed journal covering all subspecialties within ophthalmology. Key topics include: Optometry; Visual science; Pharmacology and drug therapy in eye diseases; Basic Sciences; Primary and Secondary eye care; Patient Safety and Quality of Care Improvements. This journal is indexed on PubMed

Submit your manuscript here: https://www.dovepress.com/clinical-ophthalmology-journal
13. Nishitsuka K, Nishi K, Namba H, Kaneko Y, Yamashita H. Intraoperative optical coherence tomography imaging of the peripheral vitreous and retina. Retina. 2018;38(3):e20-e22. doi:10.1097/ IAE.0000000000001979

14. Nishitsuka K, Nishi K, Namba $H$, Kaneko Y, Yamashita $H$. Quantification of the peripheral vitreous after vitreous shaving using intraoperative optical coherence tomography. BMJ Open Ophthalmol. 2021;6(1):e000605. doi:10.1136/bmjophth-2020-000605

15. Ohji M, Tano Y. Vitreoretinal surgery with slit-lamp illumination combined with a wide-angle-viewing contact lens. $\mathrm{Am}$ J Ophthalmol. 2004;137(5):955-956. doi:10.1016/j.ajo.2003.11.027

16. Nishitsuka K, Nishi K, Namba H, Kaneko Y, Yamashita H. Peripheral cystoid degeneration finding using intraoperative optical coherence tomography in rhegmatogenous retinal detachment. Clin Ophthalmol. 2021;15:1183-1187. doi:10.2147/OPTH.S306623

17. Adelman RA, Parnes AJ, Ducournau D; European Vitreo-Retinal Society Retinal Detachment Study G. Strategy for the management of uncomplicated retinal detachments: the European vitreo-retinal society retinal detachment study report 1. Ophthalmology. 2013;120 (9):1804-1808. doi:10.1016/j.ophtha.2013.01.070

18. Adelman RA, Parnes AJ, Sipperley JO, Ducournau D; European VitreoRetinal Society Retinal Detachment Study G. Strategy for the management of complex retinal detachments: the European vitreo-retinal society retinal detachment study report 2. Ophthalmology. 2013;120 (9):1809-1813. doi:10.1016/j.ophtha.2013.01.056

19. Michalewska Z, Ducournau D, Adelman RA; Group ERS. How do vitrectomy parameters influence the results of rhegmatogenous retinal detachments repair? EVRS RD Study No. 3. Acta Ophthalmol. 2014;92(5):e416-e417. doi:10.1111/aos.12318

20. Adelman RA, Parnes AJ, Michalewska Z, Ducournau D; European VitreoRetinal Society Retinal Detachment Study G. Clinical variables associated with failure of retinal detachment repair: the European vitreo-retinal society retinal detachment study report number 4. Ophthalmology. 2014;121 (9):1715-1719. doi:10.1016/j.ophtha.2014.03.012

21. Baba T, Kawasaki R, Yamakiri K, et al. Visual outcomes after surgery for primary rhegmatogenous retinal detachment in era of microincision vitrectomy: Japan-Retinal Detachment Registry Report IV. Br J Ophthalmol. 2021;105(2):227-232. doi:10.1136/ bjophthalmol-2020-315945

22. Koto T, Kawasaki R, Yamakiri K, et al. Six-months primary success rate for retinal detachment between vitrectomy and scleral buckling. Retina. 2020. doi:10.1097/IAE.0000000000002994

23. Kawano S, Imai T, Sakamoto T; Japan-Retinal Detachment Registry G. Scleral buckling versus pars plana vitrectomy in simple phakic macula-on retinal detachment: a propensity score-matched, registry-based study. Br J Ophthalmol. 2021:bjophthalmol-2020318451. doi:10.1136/bjophthalmol-2020-318451

24. Weichel ED, Martidis A, Fineman MS, et al. Pars plana vitrectomy versus combined pars plana vitrectomy-scleral buckle for primary repair of pseudophakic retinal detachment. Ophthalmology. 2006;113(11):2033-2040. doi:10.1016/j.ophtha.2006.05.038
Central and CAS, and is the official journal of The Society of Clinical Ophthalmology (SCO). The manuscript management system is completely online and includes a very quick and fair peer-review system, which is all easy to use. Visit http://www.dovepress.com/ testimonials.php to read real quotes from published authors. 